\title{
Efficiency Enhancement of Gallium Arsenide Photovoltaics Using Solution-Processed Zinc Oxide Nanoparticle Light Scattering Layers
}

\author{
Yangsen Kang, ${ }^{1}$ Dong Liang, ${ }^{2}$ Saahil Mehra, ${ }^{3}$ Yijie Huo, ${ }^{1}$ Yusi Chen, ${ }^{1}$ Mark G. Christoforo, \\ Alberto Salleo, ${ }^{3}$ and James S. Harris ${ }^{1,3,4}$ \\ ${ }^{1}$ Department of Electrical Engineering, Stanford University, Stanford, CA 94305, USA \\ ${ }^{2}$ Department of Physics, Stanford University, Stanford, CA 94305, USA \\ ${ }^{3}$ Department of Materials Science and Engineering, Stanford University, Stanford, CA 94305, USA \\ ${ }^{4}$ Department of Applied Physics, Stanford University, Stanford, CA 94305, USA \\ Correspondence should be addressed to Yijie Huo; yjhuo@stanford.edu
}

Received 10 September 2015; Revised 22 November 2015; Accepted 26 November 2015

Academic Editor: Xiaosheng Fang

Copyright (C) 2015 Yangsen Kang et al. This is an open access article distributed under the Creative Commons Attribution License, which permits unrestricted use, distribution, and reproduction in any medium, provided the original work is properly cited.

\begin{abstract}
We demonstrate a high-throughput, solution-based process for subwavelength surface texturing of a III-V compound solar cell. A zinc oxide $(\mathrm{ZnO})$ nanoparticle ink is spray-coated directly on top of a gallium arsenide (GaAs) solar cell. The nanostructured $\mathrm{ZnO}$ films have demonstrated antireflection and light scattering properties over the visible/near-infrared (NIR) spectrum. The results show a broadband spectral enhancement of the solar cell external quantum efficiency (EQE), a 16\% enhancement of short circuit current, and a $10 \%$ increase in photovoltaic efficiency.
\end{abstract}

\section{Introduction}

Gallium arsenide (GaAs) is a semiconductor used for a variety of optoelectronic applications (photodetectors, lasers, and solar cells) due to its high absorption coefficient and carrier mobility [1-3]. The best performing GaAs based solar cells have demonstrated efficiencies as high as $29 \%$ [4]. A critical loss mechanism in these devices is the reflection at the air-GaAs interface (over 30\%), caused by the large refractive index mismatch between GaAs and air. This reflection loss significantly limits the performance of GaAs solar cells and makes the antireflective structure crucial to achieving high cell efficiencies. Multilayer antireflective coatings with low reflective index materials are generally used to reduce reflection losses, but these methods are sensitive to wavelengths and incident angles $[5,6]$. Further, the precise thickness requirement for each layer makes depositing them economically unfavorable for solar cell production. Recently, nanoscale surface texturing [7-12] has been proposed as an alternative approach to achieving broadband wavelength and omnidirectional antireflection properties. However, this method typically requires complex processing techniques (such as e-beam, interference, or nanoimprint lithography) that are limited to smaller areas, making them incompatible with practical photovoltaic manufacturing approaches [7, 9]. Moreover, the textured nanoscale surfaces typically enhance surface recombination and reduce excess carrier lifetimes, resulting in decreased efficiencies [11-13]. To avoid these drawbacks, a variety of nondestructive inorganic nanoparticles coatings are being investigated for antireflection and texturing based absorption enhancements [14-17]. Among them, zinc oxide $(\mathrm{ZnO})$ is a strong candidate, since its large band gap $\left(E_{g}=3.37 \mathrm{eV}\right.$ at room temperature) makes it transparent in the photovoltaically active regions of the solar spectrum. Further, porous films of $\mathrm{ZnO}$ nanoparticles provide a graded effective refractive index as a buffer for the air/GaAs index mismatch. Meanwhile, the $\mathrm{ZnO}$ nanoparticles with a range of feature sizes comparable to the wavelengths of the utilized solar spectrum can act as light scattering layers for broadband antireflection $[14,16]$. 


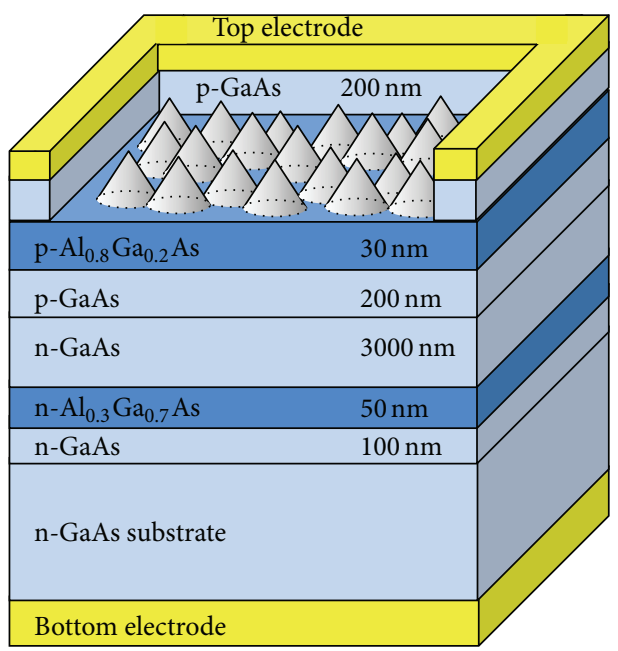

Figure 1: A schematic diagram of the $\mathrm{ZnO}$ nanoparticles coated GaAs solar cell.

By controlling the average nanoparticle size through the synthetic approach and film density through the deposition process, the optical properties of this film can be optimized for both antireflection and light scattering [18]. Here we show that the low-cost spray-deposited nanostructured $\mathrm{ZnO}$ film can enhance the performance of GaAs solar cells by its broadband antireflection and light scattering properties. The cell with optimized $\mathrm{ZnO}$ nanoparticles coating shows a $16.3 \%$ improvement in the short circuit current $\left(J_{\text {sc }}\right)$ and a $10.3 \%$ increase in overall energy conversion efficiency $(\eta)$. This low-temperature, solution-based process is compatible with other flexible substrates. These $\mathrm{ZnO}$ light scattering layers processed from nanocrystal inks could be extended to other poorly absorbing photovoltaic materials sets as well unconventional substrate materials [18].

\section{Experimental}

GaAs solar cells were grown on (100) n-GaAs substrate by metal organic chemical vapor deposition (MOCVD) with $\mathrm{Zn}$ as p-type dopant and $\mathrm{Si}$ as n-type dopant. The solar cell structure (Figure 1) includes the following: a $200 \mathrm{~nm}$ thick ptype heavily doped GaAs as a contact layer, a $30 \mathrm{~nm}$ thick ptype $\mathrm{Al}_{0.8} \mathrm{Ga}_{0.2}$ As window layer, a $200 \mathrm{~nm}$ thick $\mathrm{GaAs}$ emitter with p-type doping, and a $3000 \mathrm{~nm}$ thick GaAs base with ntype doping plus a $50 \mathrm{~nm}$ thick back side field layer of $\mathrm{n}$-type $\mathrm{Al}_{0.3} \mathrm{Ga}_{0.7}$ As. This shallow $\mathrm{p}-\mathrm{n}$ junction employed in these experiments is designed to investigate the scattering effects of $\mathrm{ZnO}$ nanoparticles film. After MOCVD growth, a multilayer metal contact of $\mathrm{Au} / \mathrm{Ge} / \mathrm{Ni} / \mathrm{Au}$ was e-beam evaporated as the bottom electrode. Metal fingers of $\mathrm{Ti} / \mathrm{Pt} / \mathrm{Au}$ were deposited as the top electrode. After both top and bottom contacts were formed, the GaAs cap layer was selectively etched in $4: 1$ citric acid (50\%) and $\mathrm{H}_{2} \mathrm{O}_{2}(30 \%)$ solution.

$\mathrm{ZnO}$ nanoparticles were synthesized using a modified procedure from Andelman et al. [19]. Briefly, $1.95 \mathrm{~g}$ of zinc acetate dihydrate, $2.94 \mathrm{~g}$ of oleic acid ( $90 \%$, technical grade), $115 \mathrm{mg}$ of gallium nitrate hydrate, and $100 \mathrm{~g}$ of 1-hexadecanol were added to a 1 liter 3 -neck flask, heated to $300^{\circ} \mathrm{C}$ for 1 hour under nitrogen gas flow, and cooled to room temperature. The $\mathrm{ZnO}$ nanoparticles were isolated from the reaction mixture by centrifugation. Ethanol was added to the reaction mixture to precipitate the nanocrystals, and the mixture was subsequently centrifuged at $4000 \mathrm{RPM}$ for 10 minutes to precipitate the nanocrystal yield. The isolated nanocrystals were washed in ethanol two more times and subsequently dried overnight under vacuum [18]. The yield was dispersed in ethanol to create a nanocrystal dispersion of concentration $1.5 \mathrm{mg} / \mathrm{mL}$. This ink formulation was the precursor solution for all spray-deposited coatings. The spray deposition process was performed using a pneumatic air-atomizing nozzle (Spraying Systems, 1/4JN-SUE15B). By independently controlling the nitrogen flow gas pressure and the precursor ink infusion rate, nanoparticle coatings with high levels of homogeneity can be achieved [18]. The process gas $\left(\mathrm{N}_{2}\right)$ was used at pressures of $2100 \mathrm{mBar}$ and the $\mathrm{ZnO}$ nanoparticle solution was infused using a syringe pump at a rate of $1.8 \mathrm{~mL} / \mathrm{min}$. The GaAs solar cell substrates were placed on a heated $X-Y$ stage $95 \mathrm{~mm}$ under the nozzle and rasterized throughout the deposition process. The resulting density of the nanoparticle coating on the substrate was calculated from the total infused volume of the $\mathrm{ZnO}$ nanoparticle precursor solution. The nominal coverage rate for the "medium concentration" optimized coating was $0.25 \mathrm{mg} / \mathrm{cm}^{2}$. The insets in Figures 2(b)2(d) show the scanning electron microscope (SEM) images of three sets of $\mathrm{ZnO}$ nanoparticles coating in which the nanoparticles have the average diameter of $250 \mathrm{~nm}-400 \mathrm{~nm}$ with the coverage fractions of nominally $35 \%, 70 \%$, and $100 \%$, respectively.

\section{Results and Discussion}

The optical properties of the $\mathrm{ZnO}$ nanoparticle layers were studied by characterizing films coated on a control glass substrate. All optical measurements were taken by a standard integrating sphere system. The sample in absorption 


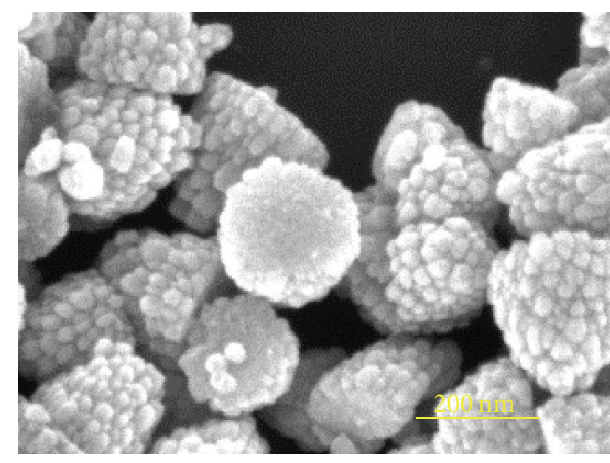

(a)

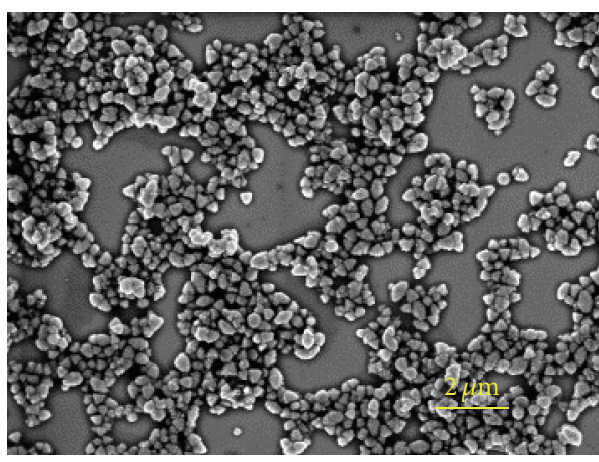

(c)

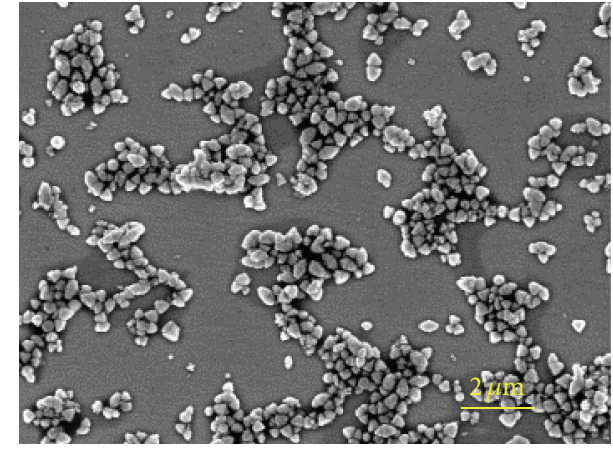

(b)

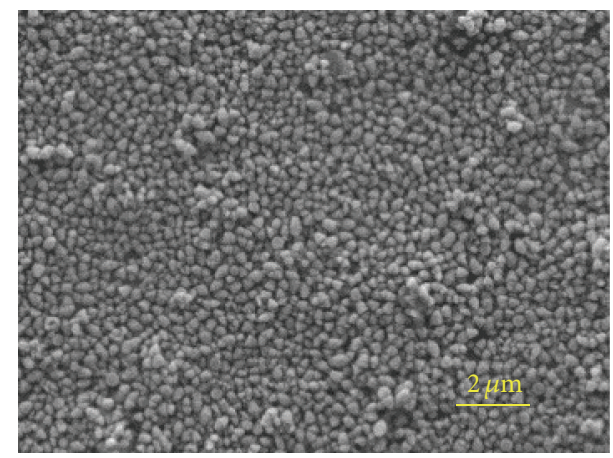

(d)

FIgURE 2: SEM top view images of $\mathrm{ZnO}$ nanoparticles coated on GaAs solar cells. (a) top view of ZnO nanoparticles; (b) low density coating, around 35\% coverage; (c) medium density coating, around 70\% coverage; (d) high density coating, $100 \%$ coverage.

measurement was mounted in the center of the sphere and illuminated by the normal incident light. All the reflected and transmitted light was collected by the integrating sphere and measured by a silicon detector mounted at the back of the sphere. The absorbance of $\mathrm{ZnO}$ nanoparticle layer is then calculated by subtracting reflected and transmitted light from the incident light. The reflectance of $\mathrm{ZnO}$ nanoparticlecoated GaAs cells was characterized by a similar method. In the total transmission measurement, the sample was placed at the opening of the sphere and illuminated by the normal incident light, thereby excluding the reflected light. Transmitted light is completely collected by the integrating sphere. The light scattered by the $\mathrm{ZnO}$ nanoparticles is characterized by subtracting direct transmission from total transmission, which is defined as the transmitted light within an angle of 2.5 degrees off-normal. In this measurement, an aperture mounted at the opening of the sphere is used to confine the angle of directly transmitted light [20]. The light scattering effect of $\mathrm{ZnO}$ nanoparticle film is illustrated by the haze ratio $(H)$, which is defined as

$$
H=\frac{\left(T-T_{d}\right)}{T},
$$

where $T_{d}$ is the direct transmittance and $T$ is the total transmittance.

Figure 3(a) shows absorption spectra of glass substrates coated with $\mathrm{ZnO}$ nanoparticles. Absorption peaks occur in ultraviolet (UV) regime $(350 \mathrm{~nm}$ to $400 \mathrm{~nm})$, which is attributed to the surface plasmonic resonance of $\mathrm{ZnO}$ nanoparticles. This absorption feature is also related to the coating densities. The lowest coverage densities result in the lowest light absorption at short wavelengths. In the visible and near-infrared (NIR) regime, nanoparticle films show gradually increased absorbance with the wavelength, which correspond to the free carrier absorption in $\mathrm{ZnO}$. Figure 3(b) shows the reflectance of GaAs solar cells coated with varying $\mathrm{ZnO}$ nanoparticle film densities. Similarly, we observe that increased $\mathrm{ZnO}$ coating densities result in lower reflectance, which is expected from the improved index matching in high density film. At shorter wavelengths, particularly from $350 \mathrm{~nm}$ to $400 \mathrm{~nm}$, the suppression of reflection is mainly caused by increased $\mathrm{ZnO}$ self-absorption. It is also important to note that the reflection properties are relatively flat across the visible and NIR light spectrum. We attribute the broadband decreases in reflection to improved index grading and reduced reflection at the top interface. This enhancement indicates that the $\mathrm{ZnO}$ nanoparticle films can reduce reflection losses and improve device absorption with minimal parasitic absorption from the nanocrystals.

In addition to improved antireflection characteristics, the $\mathrm{ZnO}$ coatings also effectively scatter the incident light due to the inherent submicron surface texturing in the porous nanoparticle films. When comparing the haze factors of the three films (Figure 4), all three samples show outstanding scattering properties with haze exceeding 0.4 over the whole spectrum. Increasing the coating coverage 


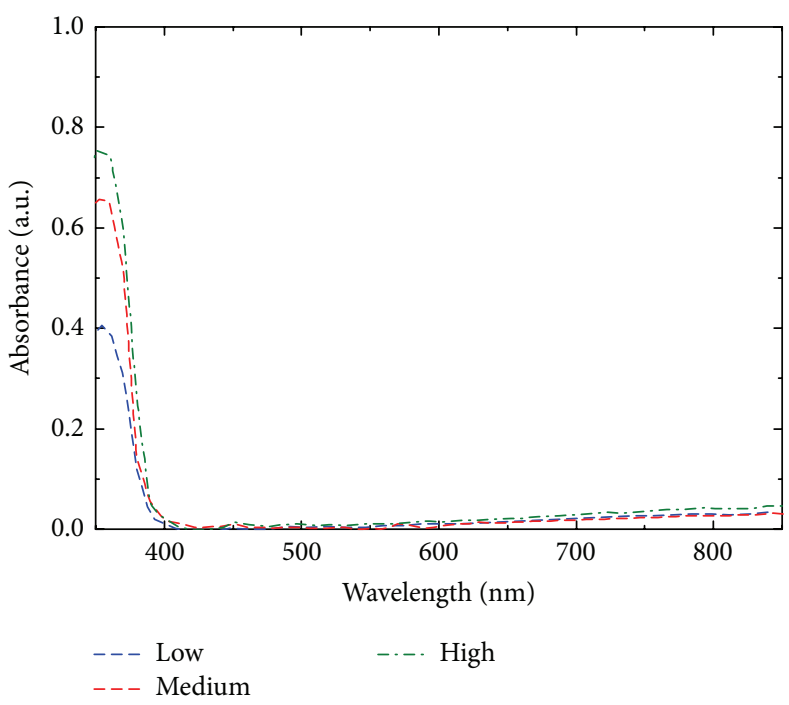

(a)

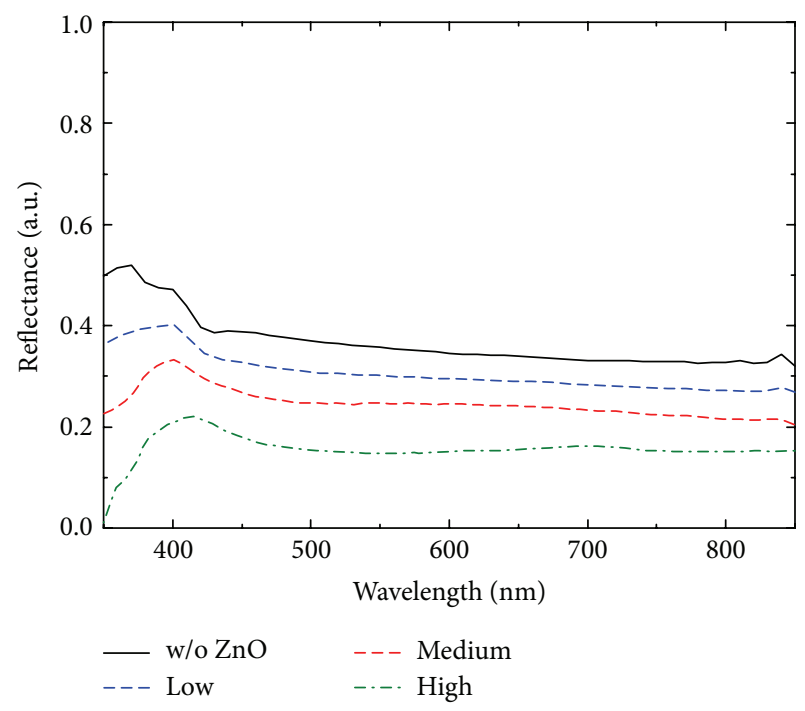

(b)

Figure 3: (a) Optical absorption of $\mathrm{ZnO}$ nanoparticle film on glass substrates; (b) reflectance of GaAs solar cells with $\mathrm{ZnO}$ nanoparticle film and control cell.

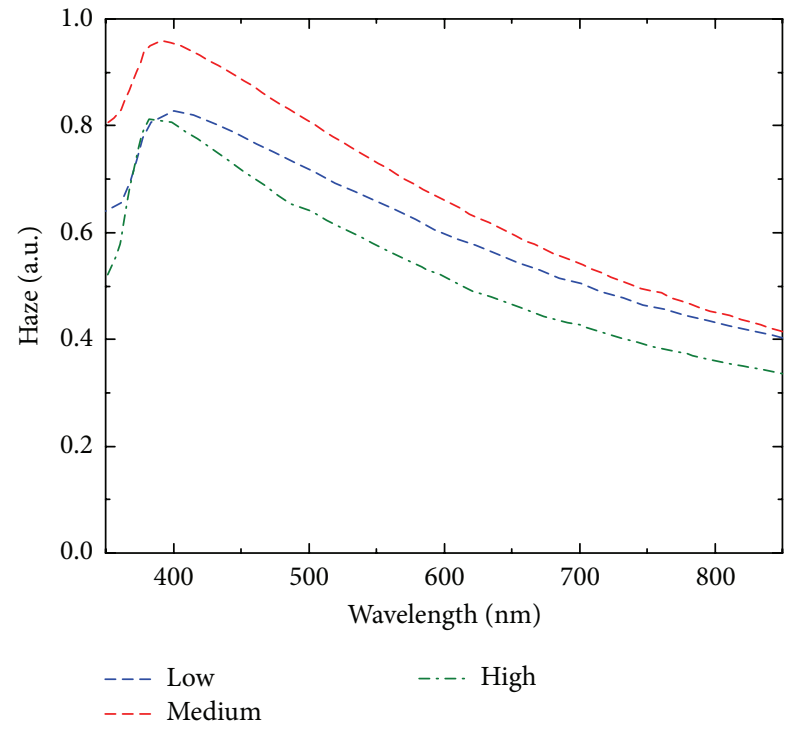

Figure 4: Haze of $\mathrm{ZnO}$ nanoparticle film coated on glass substrates with different density.

fraction from lower particle densities to medium particle densities enhances the haze factor across the visible spectrum, which indicates that stronger light scattering effects can be achieved by increasing the nanoparticle density. The highest density coating, however, is weakest in scattering power because it is more uniform than the other two coatings. This result suggests that the local nonuniformities in the moderate density coatings could be beneficial for light scattering purposes. Interestingly, the maximum haze factors of all three samples are at the wavelength of around $400 \mathrm{~nm}$, which is close to the size of the nanoparticles. This indicates that the light scattering is mainly due to the plasmonic resonance of nanoparticles. This result motivates further work to evaluate the size dependence of light scattering effects in $\mathrm{ZnO}$ nanoparticle coatings.

The photovoltaic properties of the GaAs solar cells are given in Figures 5(a) and 5(b). The $\mathrm{ZnO}$ nanoparticle films had demonstrated great enhancements on the photocurrent of the cells. To understand these enhancements, the EQEs of solar cells with nanoparticle coatings were measured and normalized to that of the reference cell without coating (Figure 5(a)). The normalized EQEs show two different trends in the UV regime $(350 \mathrm{~nm}$ to $400 \mathrm{~nm})$ and visible to NIR regime ( $400 \mathrm{~nm}$ to $850 \mathrm{~nm}$ ). In the UV regime, all the nanoparticle-coated cells have decreased photocurrent responses due to parasitic self-absorption of the $\mathrm{ZnO}$ coating. The trend is consistent with the absorption measurements in Figure 3(a). Specifically, the denser $\mathrm{ZnO}$ coating results in larger photocurrent losses. In visible and NIR regime, the medium density coating yields the highest photocurrent enhancement, which is consistent with the haze measurements of the nanoparticle films. The scattered transmitted light tends to be absorbed close to the depletion region of $\mathrm{p}-\mathrm{n}$ junction, thus enabling easier separation of photogenerated electron-hole pairs and easier collection as part of the measured photocurrent. After all, the best photocurrent enhancement was induced by the $\mathrm{ZnO}$ nanoparticle thin film as medium density coating. Figure 5(b) shows the $J$ $V$ curves of the GaAs solar cell measured before and after $\mathrm{ZnO}$ nanoparticle coating. The nanostructured $\mathrm{ZnO}$ coating demonstrated great influence on the photocurrent of the cells. The best performance was induced by the medium density nanoparticles coating with a short circuit current $\left(J_{\mathrm{sc}}\right)$ of $17.91 \mathrm{~mA} / \mathrm{cm}^{2}$, an open-circuit voltage $\left(V_{\mathrm{oc}}\right)$ of $0.94 \mathrm{~V}$, and an efficiency of $10.73 \%$. This cell with optimized $\mathrm{ZnO}$ 


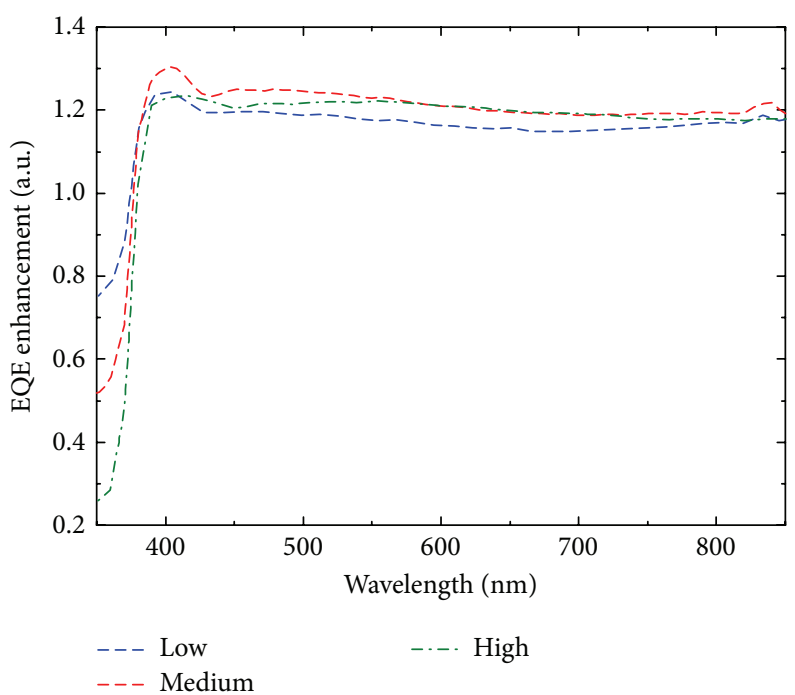

(a)

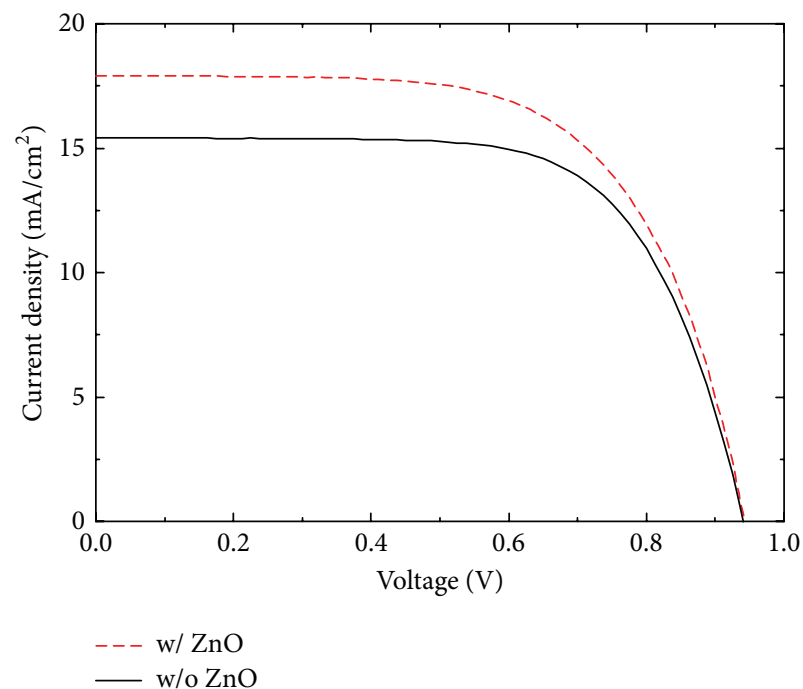

(b)

FIGURE 5: (a) EQE enhancement of the nanoparticle-coated GaAs solar cells compared with the reference cell without coating. (b) $J$ - $V$ characterization of GaAs solar cell before (black) and after (red) optimized $\mathrm{ZnO}$ nanoparticle coating (medium density) under AM $1.5 \mathrm{G}$ at room temperature.

nanoparticle coating (medium density) demonstrated a $16.3 \%$ improvement in $J_{\mathrm{sc}}$ and a $10.3 \%$ increase in efficiency compared with the same cell without $\mathrm{ZnO}$ coating.

\section{Conclusions}

In conclusion, we have shown that low-temperature, solution-processed $\mathrm{ZnO}$ nanoparticle films deposited onto GaAs solar cells provide enhanced antireflection properties, increased active layer absorption, and improved device characteristics. The highly scattering $\mathrm{ZnO}$ nanoparticle coating results in a broadband enhancement of the GaAs solar cell's EQE. The optimized coating improves the photocurrent by $16 \%$ and cell efficiency by $10 \%$ relative to control devices. This result clearly shows the potential for solution-processed light scattering layers to enhance light absorption in other photovoltaic materials. We anticipate that this method of achieving submicron surface texturing can be extended to a variety of other nanoparticle scattering agents with different physical properties (index of refraction and band gap) and potentially useful for improving light emission profiles in light-emitting diodes [21].

\section{Conflict of Interests}

The authors declare that there is no conflict of interests regarding the publication of this paper.

\section{Acknowledgments}

The authors gratefully acknowledge the technical assistance of P.-S. Wong and M. Riaziat of OEpic Semiconductors Inc. for MOCVD growth, the use of the processing facilities in the
Stanford Nanofabrication Facility, and McGehee M.D. for use of optical characterization equipment.

\section{References}

[1] M. C. Y. Huang, Y. Zhou, and C. J. Chang-Hasnain, "A surfaceemitting laser incorporating a high-index-contrast subwavelength grating," Nature Photonics, vol. 1, no. 2, pp. 119-122, 2007.

[2] J. Yoon, S. Jo, I. S. Chun et al., "GaAs photovoltaics and optoelectronics using releasable multilayer epitaxial assemblies," Nature, vol. 465, no. 7296, pp. 329-333, 2010.

[3] D. Pan, E. Towe, and S. Kennerly, "Normal-incidence intersubband (In, Ga)As/GaAs quantum dot infrared photodetectors," Applied Physics Letters, vol. 73, no. 14, pp. 1937-1939, 1998.

[4] M. A. Green, K. Emery, Y. Hishikawa, W. Warta, and E. D. Dunlop, "Solar cell efficiency tables (version 44)," Progress in Photovoltaics: Research and Applications, vol. 22, no. 7, pp. 701710, 2014.

[5] P. Doshi, G. E. Jellison Jr., and A. Rohatgi, "Characterization and optimization of absorbing plasma-enhanced chemical vapor deposited antireflection coatings for silicon photovoltaics," Applied Optics, vol. 36, no. 30, pp. 7826-7837, 1997.

[6] M. Victoria, C. Domínguez, I. Antón, and G. Sala, "Antireflective coatings for multijunction solar cells under wide-angle ray bundles," Optics Express, vol. 20, no. 7, pp. 8136-8147, 2012.

[7] Y. M. Song, S. Y. Bae, J. S. Yu, and Y. T. Lee, "Closely packed and aspect-ratio-controlled antireflection subwavelength gratings on GaAs using a lenslike shape transfer," Optics Letters, vol. 34, no. 11, pp. 1702-1704, 2009.

[8] J. Zhu, C.-M. Hsu, Z. Yu, S. Fan, and Y. Cui, "Nanodome solar cells with efficient light management and self-cleaning," Nano Letters, vol. 10, no. 6, pp. 1979-1984, 2009.

[9] J. Tommila, V. Polojärvi, A. Aho et al., "Nanostructured broadband antireflection coatings on AlInP fabricated by nanoimprint lithography," Solar Energy Materials and Solar Cells, vol. 94, no. 10, pp. 1845-1848, 2010. 
[10] D. Liang, Y. Kang, Y. Huo, Y. Chen, Y. Cui, and J. S. Harris, "High-efficiency nanostructured window GaAs solar cells," Nano Letters, vol. 13, no. 10, pp. 4850-4856, 2013.

[11] S. Jeong, M. D. McGehee, and Y. Cui, "All-back-contact ultrathin silicon nanocone solar cells with $13.7 \%$ power conversion efficiency," Nature Communications, vol. 4, article 2950, 2013.

[12] J. Oh, H.-C. Yuan, and H. M. Branz, "An 18.2\%-efficient black-silicon solar cell achieved through control of carrier recombination in nanostructures," Nature Nanotechnology, vol. 7, no. 11, pp. 743-748, 2012.

[13] K. Xiong, S. Lu, D. Jiang, J. Dong, and H. Yang, "Effective recombination velocity of textured surfaces," Applied Physics Letters, vol. 96, no. 19, Article ID 193107, 2010.

[14] Y.-J. Lee, D. S. Ruby, D. W. Peters, B. B. McKenzie, and J. W. P. Hsu, " $\mathrm{ZnO}$ nanostructures as efficient antireflection layers in solar cells," Nano Letters, vol. 8, no. 5, pp. 1501-1505, 2008.

[15] K. Nakayama, K. Tanabe, and H. A. Atwater, "Plasmonic nanoparticle enhanced light absorption in GaAs solar cells," Applied Physics Letters, vol. 93, no. 12, Article ID 121904, 2008.

[16] S.-S. Lo, D. Haung, and D.-J. Jan, "Haze ratio enhancement using a closely packed $\mathrm{ZnO}$ monolayer structure," Optics Express, vol. 18, no. 2, pp. 662-669, 2010.

[17] L.-K. Yeh, K.-Y. Lai, G.-J. Lin et al., "Giant efficiency enhancement of GaAs solar cells with graded antireflection layers based on syringelike $\mathrm{ZnO}$ nanorod arrays," Advanced Energy Materials, vol. 1, no. 4, pp. 506-510, 2011.

[18] S. Mehra, M. G. Christoforo, P. Peumans, and A. Salleo, "Solution processed zinc oxide nanopyramid/silver nanowire transparent network films with highly tunable light scattering properties," Nanoscale, vol. 5, no. 10, pp. 4400-4403, 2013.

[19] T. Andelman, Y. Gong, M. Polking et al., "Morphological control and photoluminescence of zinc oxide nanocrystals," The Journal of Physical Chemistry B, vol. 109, no. 30, pp. 14314-14318, 2005.

[20] ASTM International, Standard Test Method for Haze and Luminous Transmittance of Transparent Plastics, ASTM International, West Conshohocken, Pa, USA, 2013.

[21] W. Gaynor, S. Hofmann, M. G. Christoforo et al., "Color in the corners: ITO-free white OLEDs with angular color stability," Advanced Materials, vol. 25, no. 29, pp. 4006-4013, 2013. 

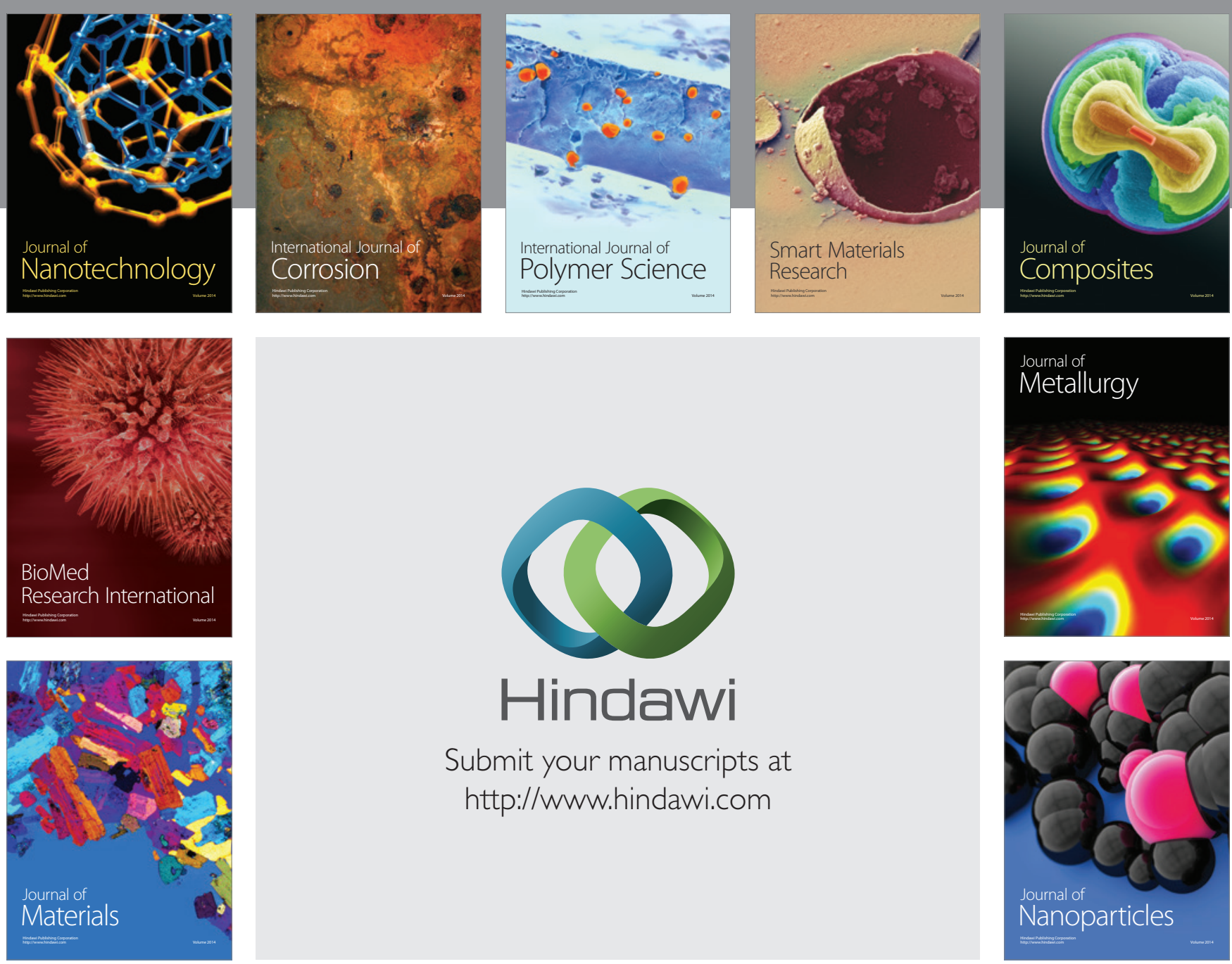

Submit your manuscripts at http://www.hindawi.com
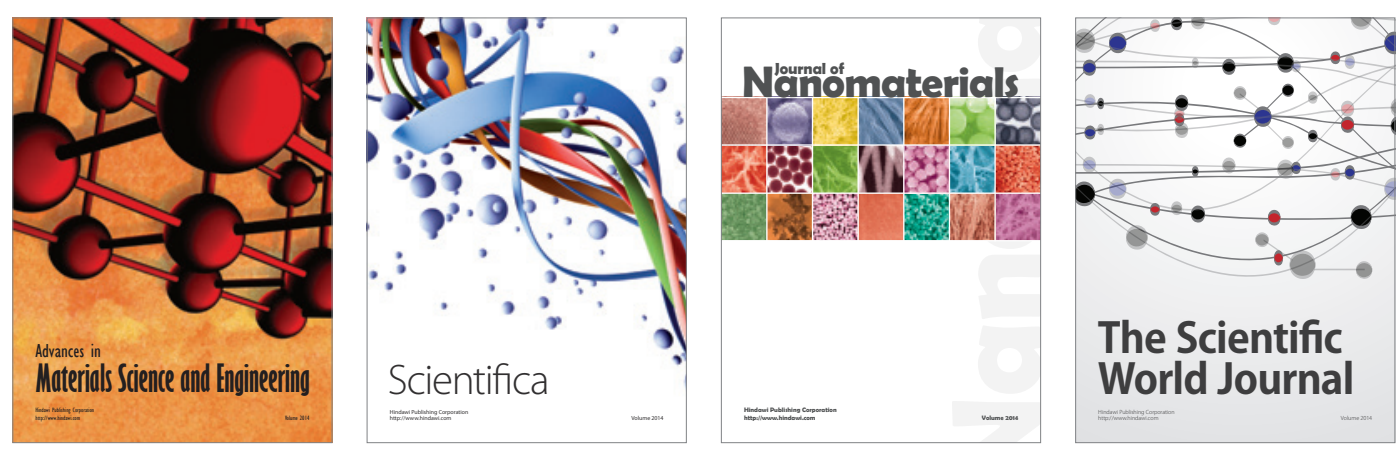

\section{The Scientific World Journal}
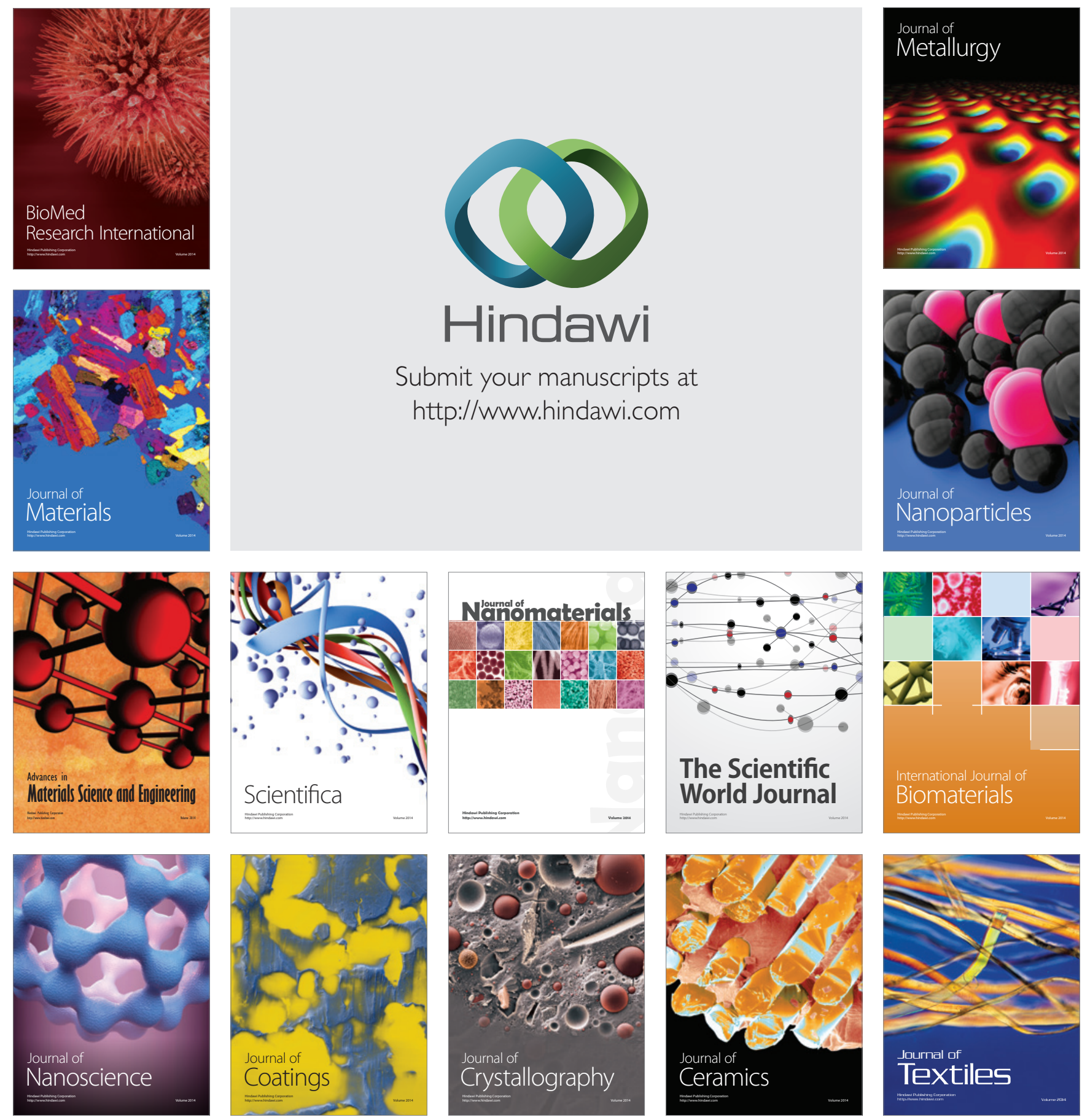